\title{
Docentes universitários e aposentadoria: uma experiência de velhice bem-sucedida?
}

\section{University professors and retirement: Experience of successful aging?}

\section{Eliane Lucia Colussi ${ }^{a}$, Vanessa Domingues Ilha ${ }^{b}$, Tadia Carolina Cogoc, Marilene Rodrigues Portellad, Helenice de Moura Scortegagna ${ }^{\text {e* }}$}

a Doutora em História pela Pontifícia Universidade Católica do Rio Grande do Sul. Professora do Programa de Pós-Graduação em Envelhecimento Humano/UPF. < colussi@upf.br>

b Mestre pelo Programa de Pós-Graduação em Envelhecimento Humano/UPF. < vailha3@yahoo.com.br>

Mestre pelo Programa de Pós-Graduação em Envelhecimento Humano/UPF. <tadiacogo@gmail.com>

d Marilene Rodrigues Portella. Doutora em Enfermagem pela Universidade Federal de Santa Catarina. Professora do Programa de Pós-Graduação em Envelhecimento Humano da Universidade de Passo Fundo/UPF. < portella@upf.br>

e Doutora em Enfermagem pela Universidade Federal de Santa Catarina. Professora do Programa de Pós-Graduação em Envelhecimento Humano da UPF <helenice@upf.br>

\section{ARTICLE INFO}

\section{Article history}

Received: 01/06/2015

Accepted: 29/06/2015

\section{Correspondent Author}

Eliane Lucia Colussi

Av. Sete de Setembro, 90/901 - Centro

99010-120 Passo Fundo, RS, Brasil

<colussi@upf.br>

\section{(C) 2014 All rights reserved}

\section{Editors}

Alfredo Cataldo Neto

Irenio Gomes

\begin{abstract}
RESUMO
O presente estudo teve por objetivo analisar as percepções e memórias de um grupo de professores universitários aposentados, quanto a sua trajetória profissional, o processo da aposentadoria e a recriação do cotidiano a partir do desligamento da instituição. Os participantes da pesquisa pertencem a um mesmo grupo profissional e origem socioeconômica. A pesquisa, de abordagem qualitativa, foi desenvolvida por meio de entrevistas semiestruturadas com um grupo de nove professores aposentados. A partir de um tópico-guia e diário de campo foi possível realizar a análise e interpretação dos dados coletados. Foram identificados os eixos temáticos mais frequentes, quais sejam: diferentes percepções das trajetórias de vida e profissional; reconstrução do cotidiano de idosos aposentados e existência de projetos de vida no período pós-aposentadoria. A análise das narrativas revelou que a satisfação com a trajetória profissional, preparação para a aposentadoria e a existência de projetos de futuro estão diretamente relacionadas à percepção de velhice bem-sucedida do grupo de participantes da pesquisa.
\end{abstract}

DESCRITORES: Envelhecimento; Satisfação pessoal; Aposentadoria; Professores universitários; Memória.

\begin{abstract}
The objective of this study was to analyze perceptions and memories of a group of retired professors, regarding to professional career, retirement process and the everyday invent anew since the superannuation. The analyzed group belongs to the same professional group and has the same socioeconomic background. The approach of the research was qualitative and was developed by means of semi structured interviews with nine retired professors. Based on a topic guide and a field diary were possible to analyze and interpret the collected data. The most frequent identified subjects were: different perceptions of life and career; reconstruction of retired professors quotidian and life plans for post-retirement period. The narrative analysis showed that satisfaction with professional career, preparation for retirement and the existence of future projects are directly related to the perception of successful aging for the studied group.
\end{abstract}

KEYWORDS: Aging; Personal satisfaction; Retirement; University teachers; Memories.

\footnotetext{
* Contribuições dos autores: As primeiras três autoras participaram da elaboração do projeto, coleta de dados e análise dos dados. Para redação do artigo a participação das demais autoras ocorre de forma efetiva.
} 


\section{INTRODUÇÃO}

Envelhecimento, aposentadoria e memória são expressões cada vez mais frequentes nos estudos acadêmicos. Os estudos que refletem sobre a interface entre velhice e aposentadoria têm se pautado em algumas questões centrais: momento da trajetória dos indivíduos vivenciado como experiência negativa e geradora de sofrimento, e negação ao desvinculo com o mundo do trabalho.

Um exemplo nesta perspectiva é a pesquisa que estudou a trajetória de seis professores universitários com mais de sessenta anos que permaneceram trabalhando ${ }^{1}$. Trata do imaginário dos professores em relação à velhice e ao sentido do trabalho e sua relação com a aposentadoria. A conclusão destacou que a aposentadoria e velhice vieram acompanhadas de sentimentos negativos como perda e incapacidade, entre outros. Dessa forma, entende-se que continuar trabalhando, bem como centrar o foco nos benefícios obtidos pelo contrato de trabalho na aposentadoria, constituiu-se numa estratégia de retardar as limitações e perda da identidade.

Ao relacionar aposentadoria e envelhecimento humano, enquanto experiência positiva de profissionais no processo de desligamento com o mundo profissional ${ }^{2}$, a perspectiva de velhice bem-sucedida a aposentadoria representa o reconhecimento e a autoestima na fase da maturidade. Pensar em experiências de velhice bemsucedida pode contribuir para a quebra de estigmas, mitos, imaginários que, no campo da subjetividade, nos remete a pensar na aposentadoria e velhice como um ponto final, a última e derradeira fase da vida.

O envelhecimento bem-sucedido é singular, pois apresenta possibilidades diversas, considerando, entre muitos fatores, as escolhas pessoais caminhos escolhidos ${ }^{3,4}$. A aposentadoria pode se configurar como um período de dúvidas e/ou expectativas, resultando em formas diferenciadas de enfrentamento deste momento. Numa perspectiva de bem-estar subjetivo, compreendido como a busca de equilíbrio diante dos estados agradáveis e desagradáveis pertinentes às situações vividas $^{5}$, as respostas do idoso podem tanto estar atreladas, como expressar uma reação, às representações construídas, ou incutidas, a partir da imagem social que permeia a aposentadoria, geralmente pautada na cristalização do binômio aposentadoria-exclusão social ${ }^{3}$.

O significado do envelhecimento bem-sucedido pode ser interpretado a partir dos aspectos relacionados às particularidades individuais e às diferenças socioculturais ${ }^{6}$. Ademais, é importante considerar nos estudos a utilização de uma análise não dissociada das questões pessoais, pois a valorização das percepções oferece a possibilidade de estabelecer o envelhecimento bem-sucedido como uma meta pessoal, continuamente modificada no curso da vida.

As pessoas com maior resiliência manifestam um melhor nível de bem-estar subjetivo e, consequentemente, a percepção de uma velhice bem sucedida ${ }^{7}$. A resiliência atrela-se a fatores emocionais e motivacionais, decisivos para a utilização do potencial de competência pessoal, bem como a causas externas, relacionadas aos estereótipos, mitos e contexto familiar e social, incluindo saúde física e mental, independência econômica, entre outros ${ }^{5,7,8}$. Na aposentadoria, a forma como se dá o enfrentamento diante da tensão resultante de processos psicossociais pode revelar possibilidades de desgaste, com consequências nocivas ou proporcionar alinhamento produtivo e saudável do indivíduo9. O presente estudo partiu da aposentadoria de docentes universitários no intuito de verificar se tal evento se configura como uma possibilidade de velhice bem-sucedida.

\section{MÉTODO}

A pesquisa exploratória descritiva é de abordagem qualitativa com nove professores. Com o intuito de identificar os prováveis participantes foi feito contato com o setor de Recursos Humanos da Instituição que forneceu uma lista de professores aposentados atendendo aos critérios: docentes que mantiveram vínculo empregatício com a Instituição por período superior a 25 anos, representativos de diferentes áreas de conhecimento e funções; aposentado pelo Plano de Aposentadoria Complementar e por jubilamento entre os anos de 2000 até o ano de 2009. Na sequência houve contato telefônico com o convite de participação na pesquisa. Mediante adesão chegou-se ao número de dez participantes, os quais foram divididos em dois grupos: cinco professores que, na maior parte da trajetória profissional, ocuparam cargos de gestão e outros cinco cuja ocupação predominante foi a docência em sala de aula. Utilizou entrevista semiestruturada, tópico-guia e o diário de campo na coleta de dados. No decorrer do processo de coleta de informações houve uma perda em função de problemas de saúde. Para entrevista houve agendamento e, em comum acordo, pactuado data, hora e local da mesma.

$\mathrm{Na}$ análise de conteúdo ${ }^{10}$, seguiu-se a proposta da análise temática que compreende três etapas: pré-análise, exploração do material e tratamento dos resultados obtidos e interpretação. No primeiro momento ocorreu a leitura do material no sentido de apreender aspectos gerais das narrativas; na continuidade identificou-se um conjunto de falas 
representativas das unidades de significação, procedeu-se a leitura e releitura exaustiva a fim de determinar as categorias apresentadas na sequência.

Preservando as questões éticas de pesquisa com seres humanos, o projeto foi submetido e aprovado pelo Comitê de Ética em Pesquisa da Universidade de Passo Fundo sob Parecer 088/2010. Neste artigo a identificação dos participantes atende ao código EX $(\mathrm{E}=$ entrevistado; $\mathrm{X}=$ número de ordem da entrevista $)$.

\section{RESULTADOS E DISCUSSÃO}

O grupo de docentes universitários aposentados tinha idades entre 60 e 81 anos. A maioria nasceu na região próxima Passo Fundo, sede da Universidade de Passo Fundo (UPF). Dos nove entrevistados apenas dois nasceram e permaneceram, a maior parte da vida, na cidade. Quatro dos docentes deslocaram-se para esse centro em busca de escolarização e oportunidades de ingresso no mercado de trabalho. Em dois casos, o que determinou a escolha foram fatores ligados à família como, por exemplo, a transferência do marido para a cidade e, em outro, o fato da professora ser filha de funcionário público transferido para esse contexto. Apenas dois entrevistados fixaram residência logo após a conclusão da formação em nível superior.

Quanto à formação em cursos de graduação, cinco dos participantes realizaram seus cursos na UPF, dois estudaram e concluíram o curso superior em Porto Alegre e dois em São Leopoldo e Viamão. Os entrevistados ministravam suas aulas nos Cursos de Odontologia, Belas Artes, Matemática, Filosofia, Medicina, Educação Física, Filosofia e Teologia e Educação/Pedagogia.

Ao iniciar a vida profissional no ensino superior eram, na sua maioria, "adultos jovens", pois estavam na faixa dos 30 anos e, com exceção de dois, já acumulavam experiência profissional em outros espaços do mundo do trabalho. Em cinco dos casos, eram professores da rede de ensino de educação básica pública ou privada. Dois já atuavam como profissionais liberais na área de saúde e dois tiveram formação superior completa ao iniciarem a vida profissional na própria Universidade.

Quanto à titulação acadêmica, um dos docentes tinha apenas a graduação, quatro eram especialistas, dois tinham mestrado e dois, doutorado. Do total, cinco ocuparam, em algum momento da vida profissional da instituição cargos administrativos na alta hierarquia: incluindo a reitoria e direção de unidade.

\section{Satisfação com a trajetória profissional}

Ser docente significou mais do que ter a responsabilidade com a formação dos alunos. E3 afirmou que sempre gostou de ministrar aula, pois, segundo ela, ser professor é uma profissão especial, pois, "a gente tem ali a pessoa na mão, e você então pode desencadear muita coisa boa, inclusive além dos conteúdos, daquilo que a gente tem obrigação de ministrar".

Tornar-se professor universitário exigiu muita dedicação, estudo, capacitação. Nas entrevistas, observou-se que a satisfação construída ao longo do processo de escolarização e de ingressar no ensino superior como docente esteve relacionada ao fato de gostar de estudar, da ciência e da cultura. Mais importante, enfatizaram o valor do trabalho em suas vidas. Nas palavras E5 se constata tal percepção: "uma coisa importante é o fato de eu sempre estudar, eu estudava ou fazia um curso. A minha experiência me deu a seguinte opinião: só existe uma vocação que é para o trabalho, e no trabalho é que eu vou construir o meu ser, o meu modo de agir, a minha compreensão do mundo".

$\mathrm{Na}$ mesma perspectiva, E8 informou que recebeu um estímulo muito grande de um colega, professor mais experiente, para direcionar sua carreira profissional. A importância do referido colega aparece em diversos momentos da entrevista. De início ela diz que foi aluna da primeira turma do professor "aqui na UPF". Para ela, foi ele que a estimulou "muito a estudar a parte da pesquisa, a parte da metodologia do conhecimento, de como se constrói o conhecimento. A única coisa que eu tinha como projeto era estudar e eu estudei bastante", afirma E8.

Estudar e trabalhar apareceu como conceitos indissociáveis. Os termos positivos em relação à escolha profissional e ao fato de que "estudar" constituía-se em projeto de vida esteve, muitas vezes relacionado às condições socioeconômicas familiares e ao desejo de ascensão social.

Para E4 havia um conflito entre ser profissional liberal, no caso médico e professor universitário, quando expressa "Eu não tinha formação de professor. Certamente isso me trouxe muita dificuldade. Eu até hoje não gosto de dar aula. Acho que professor, nos moldes clássicos, nunca soube ser, eu talvez sirva muito mais para educador do que para professor". Para ele, ser professor e ser educador se constitui em papéis diferentes. Mesmo não se considerando um bom professor, ele mencionou que contribuiu na formação dos alunos pela experiência e prática profissional. Era nos espaços de saúde, em especial nos hospitalares que, "sempre me atraiu muito mais o trabalho junto com o aluno ao redor do leito do paciente, acompanhando o doente internado, acompanhando os ambulatórios, com um aluno me acompanhando nas cirurgias" declara E4.

Outro aspecto comum evidenciado na fala dos entrevistados foi às referências sobre o que lhes conferiu merecimento para alcançar o ingresso da docência no ensino superior. Ao se examinar as trajetórias 
profissionais, verificou-se que todos os participantes da pesquisa haviam acumulado experiências profissionais consistentes, e destaque nas suas áreas de atuação. Para os docentes aposentados, o termo mérito sintetizou o espírito de tal conquista. Importante que se ressalte que no período em questão, a realidade do ensino superior brasileiro estava muito distante das atuais exigências para se trilhar o ingresso e permanência como docente universitário.

Os entrevistados fazem parte de uma geração de professores universitários em que o ingresso na instituição obedecia a regras bastante peculiares. Em se tratando de uma universidade privada do interior do Brasil, nas décadas de sessenta e setenta do século passado, não foi titulação, capacitação e mérito por concurso que os selecionou para o mundo acadêmico universitário. Os requisitos que abriram as portas da universidade para suas carreiras se restringiram ao fato de serem profissionais reconhecidos em outros espaços de atuação. Acrescente-se a isto, outra modalidade bastante comum de recrutamento: os laços de amizade e a "indicação pessoal".

E1 relatou o seu ingresso de forma reveladora de situações que certamente foram comuns. Ele começou a ministrar aulas no período em que ainda era estudante do curso de graduação. No primeiro ano, tendo com 20 anos de idade, havia carência de professores, assim "o professor que dava Anatomia, quando nós passamos para o segundo ano, ele começou a olhar os alunos que poderiam auxiliá-lo; então ele foi escolhendo”. Assim, sendo aluno no segundo ano de faculdade, iniciou na docência. Em situação semelhante, E7 começou a ministrar aulas, como monitor, antes de concluir o curso superior.

As situações de indicações pessoais ficam mais evidentes em relação ao ingresso da participante E2, que foi convidada para substituir uma docente que havia se aposentado. Também E3 e E8 iniciaram suas atividades por convite pessoal. No caso da E3, ainda faltava um ano para concluir o curso de licenciatura em Matemática quando recebeu o convite para ministrar aulas no mesmo curso. Já E8 estava graduada, porém sua irmã, professora na instituição, promoveu o contato com os dirigentes facilitando sua entrada.

\section{Tempo de aposentadoria, reorganização de uma trajetória}

As circunstâncias que prescrevem a aposentadoria corroboram a trajetória pessoal construída no curso do viver e envelhecer, ajuíza também a capacidade que o indivíduo tem de exercer controle sobre a própria vida. Por conseguinte, o momento da aposentadoria concerne às escolhas pessoais de comportamento durante o processo de envelhecimento e à preparação para a aposentadoria ${ }^{11,12}$.

$O$ período da aposentadoria, bem como o seu planejamento revelam as experiências diferenciadas vividas pelos participantes do estudo. Quatro deles declararam explicitamente que planejaram e decidiram pela aposentadoria de forma espontânea. Três levaram em consideração o fato de terem completado 60 anos de idade, exigência para usufruir do Plano de Aposentadoria Complementar. Outros três já recebiam rendimentos da aposentadoria por tempo de serviço pelo Instituto Nacional do Seguro Social e acumulavam rendimento como professores aposentados da rede estadual de ensino.

No caso de E7, E3, E6 e E8 a aposentadoria foi pensada, refletida, calculada financeiramente e discutida em família. Verifica-se que as perdas, muitas vezes, não são apenas as emocionais, afetivas ou de ausência de atividade laboral. A aposentadoria, mesmo para esse grupo de entrevistados que acumulam remunerações de duas ou mais fontes de renda, são ainda, num primeiro momento, produtividade material.

E7 revelou sua experiência com o prévio planejamento e as reflexões que foram acompanhando o amadurecimento da decisão. Para ele pesou muito os aspectos financeiros, pois já acumulava duas aposentadorias. Chama atenção o fato de que se preocupou em preparar a instituição para sua saída, pois poderia ter se desligado antes do final do ano letivo, mas revela seu pensamento na ocasião, ao comentar: "não vou deixar a universidade na mão nem os meus alunos que eu sempre respeitava"; complementou o relato de sua experiência afirmando que sua motivação principal foi à financeira. Como confere suas palavras: "a sorte que a Universidade tinha feito há vários anos atrás aquele plano de aposentadoria com o Banco do Brasil. Ele não é cem por cento, mas você consegue equilibrar a tua vida".

Outro caso exemplar foi de E6, pois a decisão da aposentadoria levou em conta, o contexto familiar. No seu relato, evidencia-se uma percepção crítica: ela se considerava "defasada academicamente". Mesmo não tendo optado pelo Plano de Previdência Complementar, ela se desligou da instituição com 59 anos de idade. A justificativa para a tomada de decisão foi assim relatada:

Eu tinha a minha mãe com bastante idade e estava ficando difícil eu conciliar tudo; aí eu achei que eu não dava mais conta e outra coisa foi o seguinte: eu não tinha tempo para entrar num trabalho de pesquisa, numa coisa assim; eu já tinha voltado dos Estados Unidos há 16 anos e eu sentia que eu precisava me renovar. Eu pensei: ou te renova ou sai e dá lugar para gente nova. (E6) 
Questões pessoais, familiares ou pertinentes ao contexto profissional podem colaborar na tomada de decisão pelo momento da aposentadoria, o que inclui ainda, indicador financeiro pessoal ou familiar e a perspectiva de tempo vindouro disponível para engajamento em futuros projetos ${ }^{12}$.

E3 optou pela aposentadoria em momento especial da carreira: ocupava um alto cargo na direção da instituição e não havia ainda completado nem o período de final de gestão e nem a idade mínima de 60 anos para usufruir integralmente da aposentadoria complementar. Outros fatores justificaram sua decisão: "por razões assim um pouco de balizar, até porque a minha saúde não estava indo muito legal, com todas as questões que a gente tem inerentes ao cargo, eu optei por me preservar do ponto de vista de saúde". As precedências no momento da retirada da vida laboral foram de manter um curso de envelhecimento priorizando cuidados com a saúde, uma conjuntura endossada por estudiosos ${ }^{12,13}$.

As circunstâncias que circundam o planejamento da aposentadoria trouxeram algumas reflexões importantes sobre o advento da velhice. E3 comentou que "alguns jovens ficam relutando, mas a gente não pode pensar que a gente vai ser jovem a vida inteira! No sentido da energia física e de ter o trabalho e de poder responder a um trabalho". O curso da vida aliado as transformações fisiológicas requerem a revisão de papeis, e, E3 percebe como algo natural esse processo ao mesmo tempo que menciona como extremamente positivo fato de existir um Plano de Aposentadoria Complementar, pois concede a "dignidade de tu permaneceres em um patamar". A atitude positiva perante a vida manifestada por E3 corrobora a premissa de um envelhecimento bem sucedido ${ }^{6,14}$.

Por outro lado, o relato de E5 ilustra um processo acompanhado de perdas funcionais, logo no início da entrevista, ele informou que sofria do Mal de Parkinson. Para ele, as mãos trêmulas e o enrijecimento dos músculos não foram as maiores dificuldades. Seu sofrimento transpareceu ao expor:

Minha dificuldade maior é a lógica do pensar. Por exemplo, quando eu estou falando com você, de repente me desaparece a narração e eu demoro em recompor-me e outras vezes eu não consigo. Mas, antes de eu me aposentar, no último ano, eu trabalhei; eu tinha um tema que eu preparava junto com um colega, mas eu fazia um esforço máximo para que ele assumisse, pela dificuldade que eu tinha, eu cansava demais e muita dificuldade do uso do raciocínio. (E5)

A doença de Parkinson é uma síndrome clínica, patológica e bioquímica, entre suas manifestações encontram-se anormalidades de postura e equilíbrio, porém a disfunção cognitiva torna a pessoa ainda mais incapacitante, além de repercutir em uma baixa qualidade de vida ${ }^{15}$.
A condição do jubilamento foi adotada por quatro entrevistados para se desligar da instituição. $\mathrm{O}$ ato de ser jubilado constitui-se na aposentadoria compulsória, constante no regimento da universidade, que estabelece 70 anos como idade máxima para a permanência na instituição como docente. Três dos professores que encerraram a carreira profissional, nesta situação, revelaram que ainda se sentiam em plenas condições de trabalhar e que o desligamento compulsório foi "injusto". E2 relatou que ela foi "jubilada com todas as honras, todas as glórias do Conselho Universitário, com respeito de todo mundo; ser abençoada, ter saúde para chegar aos setenta com pique para continuar mais... eu só parei porque eu tinha que parar".

Se para a E2 transparece um sentimento contraditório entre "receber as honras" e ter "pique para continuar", E1 expressou sentimentos negativo em relação ao contexto da aposentadoria compulsória. Pode-se dizer que o seu vínculo com a instituição foi tão orgânico que, mesmo depois de aposentado, manifestou seu desejo de se fosse possível, retornar. Manteve-se na instituição por 48 anos, sendo que desses, 25 anos ele foi chefe de departamento. Nos últimos anos de atuação profissional, o docente percebeu situações que colocavam em campos distintos os "velhos" e os "novos" professores. Na sua narrativa, transparecem algumas aflições sentidas no período da aposentadoria:

O que acontece é que quando você está para se aposentar já começam aparecer outras pessoas para ocupar o seu lugar e eles começam a te judiar, te cortar horário, corta isso, corta aquilo... Como se dissessem assim 'vai embora'! Isso doeu, e não só eu. Você vai falar com outros, todos vão dizer a mesma coisa. Fui eu que idealizei tudo aquilo lá. (E1)

Portanto, se para alguns, rememorar a trajetória profissional significa valorização e orgulho, para outros docentes, a realidade foi percebida de forma mais dolorosa. A instituição, seu modelo políticoadministrativo, as necessidades de renovação deixaram marcas profundas. Hopf ${ }^{16}$, em estudo similar, concluiu que uma parte minoritária dos seus sujeitos de pesquisa revelou fatores que interferiram negativamente no processo de aposentadoria. Nas suas conclusões foi mencionado que entre os fatores estariam às relações interpessoais com colegas no local de trabalho.

Nas narrativas dos entrevistados foram comuns as referências ao período imediatamente anterior ao desligamento. Os sentimentos e o relacionamento com os colegas de trabalho, com administração da Universidade e a rotatividade de profissionais parece ter sido marcante. A exaltação da importância atribuída 
ao momento aparece na narrativa de E7 que, ao se aproximar da fase de sair da "ativa”, deparou-se com a seguinte situação:

Quando chegou perto da aposentadoria, meus colegas começaram: tu vais te aposentar ano que vem? Sim, pretendo! Então cuidado com o estresse do aposentado. E dali a alguns dias de novo: você está cuidando com o estresse do aposentado? Aí eu falei: vocês estão discutindo o meu problema ou estão pensando no dia que vocês se aposentarem?

Nesta perspectiva, E4 relatou como foi o seu processo de preparação para a aposentadoria e de que forma percebeu a necessidade de desengajamento do mundo do trabalho. Ele foi professor da instituição desde a criação da faculdade até o jubilamento. Trabalhou ali pelo menos 35 anos. $O$ fragmento a seguir é rico em informações e percepções:

Tem uns colegas, que não gostam do jubilamento; eu acho bem interessante, porque se você tem um prazo para que um professor seja jubilado, isso é, quando você atinge setenta anos. Eu acho que tem que haver um limite, talvez tenha que haver alguma coisa, não a obrigatoriedade. Tem muito professor que prefere ser jubilado. Tem professores que se aposentam alguns dias antes de serem jubilados para não dizerem o seguinte: fui jubilado. (E4)

Nesse ponto, o entrevistado vai além de rememorar o seu próprio jubilamento, acrescentando nessa temática um problema que parece ser preocupação de muitos docentes. Mais interessante na fala do E4 é que ele se posiciona favorável e propõe alternativas chamando a atenção dos gestores para "não desperdiçar a experiência dos docentes" que, aos setenta anos de idade, se consideram em plenas condições de dar continuidade a sua vida profissional docente.

\section{Perspectivas para além da aposentadoria}

Os relatos dos nove docentes participantes do estudo demonstraram que o momento que antecedeu a aposentadoria foi permeado por sentimentos e percepções contraditórias. A insegurança em relação ao futuro expressou, muitas vezes de maneira subjetiva, o temor da chegada à velhice. Nem sempre o pensar ou optar pela aposentaria se revela na existência de projetos de futuro como forma de recriar o cotidiano. Nesse alinhamento, a aposentadoria disponibiliza tempo que pode ser destinado ao lazer, algo escasso na atividade laboral, oportunidade para que experiências de envelhecimento bem-sucedidas possam ser vivenciadas ${ }^{17}$.

Schneider e Irigaray ${ }^{11}$ acrescentam que os estudos atuais sugerem que os idosos podem apresentar uma imensa capacidade de se adaptar a novas situações e de pensar estratégias que sirvam como fatores protetores. $O$ conceito de resiliência, que pode ser definido como a capacidade de recuperação e manutenção do comportamento adaptativo, mesmo quando ameaçado por um evento estressante, e o de plasticidade, caracterizado como o potencial para mudança, são vividos pelos idosos e constituem fatores indispensáveis para um envelhecimento bemsucedido.

Ao se aposentar, a sensação inicial do indivíduo parece ser de profunda desorientação, pois, o profissional, não foi acostumado a dispor de todo o tempo livre de obrigações e para dedicá-lo ao que quiser. Exemplar desse sentimento aparece na fala de E1:

O que muda é você acostumado a um ritmo, e você não pode ficar sem fazer nada. O que acontecia antes, quando eu tinha muitos compromissos, eu tinha tempo para fazer as coisas, agora que eu não tenho nada, eu não tenho tempo: você vai fazer uma coisa [...] não eu faço depois, e depois não faz.

Existem fatores individuais que se destacam quando se observa que alguns profissionais veem a aposentadoria de forma tranquila. Nas entrevistas verificou-se, inclusive, a existência de um sentimento de alívio pela diminuição de obrigações. E3 percebe ser merecedora das vantagens da aposentadoria, pois trabalhou 35 anos. Ela enfrentou questionamento de colegas e amigos que lhe perguntavam "tu não estás fazendo nada?" Para ela, velhice bem-sucedida está relacionada à liberdade de ir e vir, de recriar seu cotidiano a partir do prazer de decidir como será seu projeto de futuro, mesmo que tal projeto seja apenas aproveitar o tempo livre, conforme expressa na fala:

Quando eu achar que vou querer fazer alguma coisa, eu vou! Ah, é bom não ter hora para levantar, levantar e deitar na rede, ler o jornal, tomar um café como a gente não toma quando está trabalhando. A gente levantava, tomava um café com uma bolacha. Hoje tu podes fazer um café que a gente merece! Quando está com vontade de cozinhar, faço alguma coisa, e eu gosto de passear e de viajar também e a gente tem viajado bastante. (E3)

Para E1, a velhice bem-sucedida foi preparada ao longo da vida, pois refere que sempre se cuidou, fez atividades físicas e dedicou tempo ao lazer, nesse seguimento se evidencia o nível satisfatório da qualidade de vida. E4 aborda sua preparação para a aposentadoria com os detalhes do planejando, substituindo atividades rotineiras, preenchendo o tempo que num futuro próximo, seria ocioso. Como se confere: 
Junto ou um pouco antes do jubilamento, eu também diminui a minha atividade profissional de consultório. Então eu fui me adaptando muito, como eu tinha esse envolvimento com o projeto do hospital; eu mantive esse envolvimento porque eu ainda sou o coordenador do projeto, então eu continuo participando, eu continuo tendo contato, principalmente com a direção da faculdade e com aqueles professores que frequentam mais a sala dos professores. (E4)

Permanecer em contato com os colegas, com os espaços da faculdade e do hospital, se atualizar e contribuir com sua experiência são prerrogativas de um envelhecimento bem-sucedido vivenciado por E4. Além disso, relatou que foi ampliando o tempo dedicado ao lazer e a família, gradativamente. Manter-se atualizado sobre sua área profissional, mesmo não trabalhando sistematicamente e redimensionar o tempo para atividades prazerosas parecem ter o mesmo significado para esse docente aposentado.

Descobrir como seria a vida fora da instituição, o ateliê, as exposições e a família foram algumas das "boas descobertas" de E2. O presente, o passado e, novamente, o presente aparecem nas suas lembranças quando ela reconhece gratamente a oportunidade de ter trabalhado na Instituição. Essa experiência foi de muita importância, pois, segundo ela:

A oportunidade que a Instituição me ofereceu pelo meu trabalho, quer dizer, acho que sentiram o meu trabalho com força e eu ter tido oportunidade de realizar a minha pesquisa. Nesse aspecto eu tenho o maior sentimento, o maior carinho pela Instituição. Fui valorizada, isso que eu senti a valorização do professor.

Para E7, ter se aposentado e reconhecer que vive uma velhice bem-sucedida está relacionado, no primeiro plano, as relações familiares. Acredita que ter sido um profissional reconhecido e correto, ter encaminhado os filhos para traçar seus caminhos e, ter sempre compartilhado com a esposa atividades e grupos vinculados à comunidade foi fundamental. Ele e a esposa sempre participaram de atividades na sua comunidade religiosa católica. Sua opinião sobre o envolvimento voluntário com a comunidade como um elemento importante da sua velhice bem-sucedida é corroborado por estudos $6,11,12,13,14$

Assim, uma velhice bem-sucedida é percebida pelos participantes do estudo, pela facilidade ou não de recriar o cotidiano após a aposentadoria. Para alguns, dar continuidade ao vínculo com o mundo do trabalho, mesmo aposentados foi a melhor opção. Foi o caso específico de E8 e de E9. Sentirem-se valorizados, competentes, atualizados estimulou sua permanência em grupos de pesquisa, realizando palestras, conferências ou aceitando ocuparem cargos ou funções de destaque na comunidade.

Contudo, para a maioria dos participantes da pesquisa, o esforço centrou-se em reinventar o cotidiano sem compromissos inerentes ao trabalho. Lazer, trabalho voluntário, viagens, dedicação à família, passaram a ocupar e dar sentido a vida pós-aposentadoria. A narrativa de E2 expressa um otimismo frente ao envelhecer. Muito provavelmente suas palavras se aproximem em muito das definições de velhice bemsucedida. A escolha da docente indica não dar espaço a sentimentos e impressões negativas e melancólicas sobre a vida e a velhice. Segundo ela: "sabe que eu fico pensando, analisando... todos os dias eu tenho uns minutos para mim de reflexão... eu tenho uma alegria interior, não sei te explicar o que é. Mesmo no sofrimento eu tenho algo dentro de mim que não me deixa abater".

No presente estudo, velhice, aposentadoria e trabalho apareceram de forma predominante, enquanto conceitos fundamentais para o paradigma da velhice bem-sucedida, em especial, quando o envelhecimento bem-sucedido pode ser alcançado por uma sequência de seleção, otimização e compensação ${ }^{18,19}$. A etapa da seleção consiste no direcionamento eletivo do desenvolvimento, incluindo a escolha das estruturas disponíveis para a obtenção satisfatória de metas. Essas metas são redefinidas conforme a repercussão das perdas nas atividades individuais e sociais. A otimização é o processo de potencializar os meios selecionados para o percurso, envolvendo o uso de recursos internos e externos para que o resultado seja eficiente. A compensação associa-se à otimização e se caracteriza pela aquisição ou ativação de novos meios e aprendizagens para compensar o declínio que coloca em risco a funcionalidade efetiva ${ }^{18,19}$.

Nesta perspectiva, a busca contínua de uma maneira efetiva de lidar com as perdas por meio de estratégias psicológicas, alocando-se recursos internos e concretos se aproxima de uma teoria de desenvolvimento adaptativo. As narrativas de E2, E8 e E9 ilustram os recursos mobilizados na direção de uma velhice bem sucedida. Mesmo os que tiveram maior dificuldade para o desligamento com o vínculo empregatício, construíram uma percepção positiva desta fase da vida, diferentemente dos resultados que atribuem a velhice $o$ significado de perdas e incapacidades, encontrados por estudo com professores universitários aposentados que continuaram trabalhando após os 60 anos de idade ${ }^{1}$.

\section{CONSIDERAÇÕES FINAIS}

A satisfação com a trajetória escolar e profissional escolhida é percebida pelo grupo de professores 
aposentados como fator favorável para uma velhice bem-sucedida. A maioria destacou o valor da docência e da escola como espaço central nas suas vidas. A importância da escolarização e da vivência em atmosfera culturalmente rica e diversificada transparece como aspecto definidor da satisfação profissional.

A aposentadoria é um momento envolto por uma série de situações críticas as quais podem interferir na qualidade de vida da pessoa, todavia os resultados mostraram as possibilidades de realocação do investimento outrora relacionado ao mundo do trabalho para outras atividades sejam elas de lazer, de voluntariado ou mesmo um novo direcionamento profissional, que já estivessem sendo pensadas como preparação para este momento da vida.

No eixo central das falas dos entrevistados evidenciam-se sujeitos tentando reconstruir-se no contexto da temporalidade advinda da aposentadoria. Cada um, ao seu jeito, redimensionou sua vida. Como protagonistas de suas histórias a aposentadoria segue uma trajetória ora bem-sucedida, ora em construção.

\section{REFERÊNCIAS}

1. Moreira JO. Imaginários sobre aposentadoria, trabalho e velhice: um estudo de caso com professores universitários. Psicologia em Estudo. 2011;16(4):541-50.

2. Veiga IPA. Eu, professora: uma narrativa autobiográfica. Linhas Críticas. 2010;16(30):183-91.

3. Guerra ACLC, Caldas CP. Dificuldades e recompensas no processo de envelhecimento: a percepção do sujeito idoso. Ciência \& Saúde Coletiva. 2010;15(6):2931-40.

4. Paschoal SMP. Qualidade de vida na velhice. In: Freitas EV et al, org. Tratado de geriatria e gerontologia. $2^{-}$ed. Rio de Janeiro: Guanabara Koogan; 2006. p. 147-53.

5. Resende MC, Ferreira AA, Naves GG, et al. Envelhecer atuando: bem-estar subjetivo, apoio social e resiliência em participantes de grupo de teatro. Fractal: Revista de Psicologia. 2010;22(3):591-608.
6. Teixeira INDO, Neri AL. Envelhecimento bem-sucedido: uma meta no curso de vida. Revista Psicologia USP. 2008; $19(1): 81-4$

7. Fernández-Ballesteros, R. Quality of Life in old age. Problematic issues. Applied Research Quality of Life. 2011;10:21-40

8. Mendes TS, Envelhecentes e resiliência: sujeitos psicológicos como capital social. Revista RBCEH. 2012;9(1): $35-45$.

9. Zanelli JC. Processos Psicossociais, bem-estar e estresse na aposentadoria. Revista Psicologia Organizações e Trabalho. 2012;12(3):329-40.

10. Minayo MCS. O desafio do conhecimento: pesquisa qualitativa em saúde. 9a ed. São Paulo: Hucitec-Abrasco; 2006. p. 406.

11. Schneider RH, Irigaray TQ. O envelhecimento na atualidade: aspectos cronológicos, biológicos, psicológicos e sociais. Estudos de Psicologia. 2008;25(4):585-93.

12. Gutierrez HC; Hershey DA. Age differences in expected satisfaction with life in retirement. Int J Aging Hum Dev. 2014;78(2):93-114.

13. Costa G. Work and ageing. Med Lav. 2010;101(Suppl 2): 57-62.

14. Depp CA, Jeste DV. Definitions and predictors of successful aging: a comprehensive review of larger quantitative studies. Am J Geriatr Psychiatry. 2006;14:6-20.

15. Azevedo MM, Galhardo MC, Amaral AKFJ, et al. Caracterização dos distúrbios cognitivos na doença de parkinson. Rev Cefac. 2009;11:251-7.

16. Hopf ACO. Fico ou vou embora? Os sentimentos expressos por professores diante da aposentadoria. Revista de Educação Física/UEM. 2002;13(2):89-96.

17. França LHFP, Soares DHP. Preparação para a aposentadoria como parte da educação ao longo da vida. Psicologia: Ciência e Profissão.2009;29(4):738-51.

18. Baltes PB, Kahn RL. On the incomplete architecture of human ontogeny: selection, optimization, and compensation as foundation of developmental theory. Am Psychol. 1997;52:366-80.

19. Baltes P, Smith J. New frontiers in the future of aging: From successful aging of the young old to the dilemmas of the fourth age. Gerontology. 2003;49(2):123-35. 